\title{
Synthesis, Spectroscopic Properties and Structural Studies of Copper(II) Complexes of \\ 2-Substituted-1,3-Diphenyl-1,3-Propanedione, Their 2,2'-Bipyridine and 1,10-Phenanthroline Adducts
}

\author{
H. Oluwatola Omoregie ${ }^{1}$, Nelson Obi-Egbedi ${ }^{1}$ \& Joseph Woods ${ }^{1}$ \\ ${ }^{1}$ Department of Chemistry, Faculty of Science, University of Ibadan, Ibadan, Oyo-State, Nigeria \\ Correspondence: H. Oluwatola Omoregie, Department of Chemistry, Faculty of Science, University of Ibadan, \\ Ibadan, Oyo-State, Nigeria. E-mail: tolaomoregie@gmail.com
}

Received: June 16, 2013 Accepted: July 1, 2013 Online Published: January 25, 2014

doi:10.5539/ijc.v6n1p71 URL: http://dx.doi.org/10.5539/ijc.v6n1p71

\begin{abstract}
The complexes of 2-substituted-1,3-diphenyl-1,3-propanedione with copper(II) ion and their 2,2'-bipyridine and 1,10-phenanthroline adducts were synthesised and characterised by microanalysis, conductance, magnetic and spectral measurements. The conductance data showed that $[\mathrm{Cu}(\mathrm{dbm})(\mathrm{phen})](\mathrm{dbm})$ and $[\mathrm{Cu}(\mathrm{Me}-\mathrm{dbm})($ phen $)](\mathrm{Me}-\mathrm{dbm})$ are 1:1 electrolytes. The infrared spectra revealed the different shifts of the carbonyl frequency. While the electronic solid reflectance spectra of the prepared complexes exhibited three peaks with varying $\lambda_{\max }$ between $12,121-21,505 \mathrm{~cm}^{-1}$, the adducts displayed single bands in the visible region between 13,553-14,698 $\mathrm{cm}^{-1}$ except for $[\mathrm{Cu}(\mathrm{dbm})(\mathrm{phen})](\mathrm{dbm})$ and $[\mathrm{Cu}(\mathrm{Me}-\mathrm{dbm})(\mathrm{phen})](\mathrm{Me}-\mathrm{dbm})$ with additional two peaks. These peaks have been assigned as d-d transitions. Using Density Functional Theory (DFT) and Semi-empirical PM3, the modeled compound showed a distorted five coordinate square pyramidal geometry.
\end{abstract}

Keywords: 2-substituted-1-phenyl-1,3-butanedione, spectra studies, magnetic susceptibility, elemental analyses, DFT

\section{Introduction}

$\beta$-diketonates have been used as shift reagents for the structural determination of steroids and other complex molecules (Hinckley, 1969, 1970). Metal $\beta$-diketonates have also been used in fuel additives; trace metal analysis by gas chromatography and other numerous extraction applications (Wenzel, 1985). We have recently reported the magnetic and spectral properties of nickel(II) complexes of 2-substituted-1,3-diphenyl-1,3-propanedione and their 2,2'-bipyridine and 1,10-phenanthroline adducts and were able to correlate the band shifts with the positive inductive effect of the substituted alkyl group on the system (Woods et al., 2009). These studies have been extended to the copper(II) derivatives of 2-substituted-1,3-diphenyl-1,3-propanedione [R-dbmH, where R = methyl (Me), ethyl (Et) and normal-butyl $(\mathrm{n}-\mathrm{Bu})$ ] and their 2,2'-bipyridine (bipy) and 1,10-phenanthroline (phen) adducts to investigate the effects of these substituents on the properties of these compounds. Density functional theory is a widely used method for electronic structure calculations and provides useful predictions for molecular parameters (Perdew et al., 2005). In this paper, we present our report on synthesis, microanalysis, conductance, magnetic and spectral measurements of Copper(II) complexes of 2-substituted-1,3-diphenyl-1,3-propanedione, their 2,2'-bipyridine and 1,10-phenanthroline adducts and the DFT and PM3 calculations of $\mathrm{Cu}(\mathrm{Me}-\mathrm{dbm})_{2}$ bipy.

\section{Method}

The following reagents were used: 1,3-diphenyl-1,3-propanedione or dibenzoylmethane (dbmH) (Aldrich chemicals), potassium carbonate, copper acetate, methyl iodide, ethyl iodide, n-butyl iodide (Aldrich chemicals), 2,2'-bipyridine and 1,10-phenanthroline (Analytical grade).

\subsection{Synthesis of the Ligands}

2-alkyl-1,3-diphenyl-1,3-propanediones were prepared as previously reported (Patel \& Woods, 1990a). 


\subsection{Synthesis of the Complexes and Adducts}

\subsubsection{Synthesis of $\mathrm{Cu}(\mathrm{dbm})_{2}$}

1,3-diphenyl-1,3-propanedione (1.7972 g, $8 \mathrm{mmol})$ which was dissolved in $10 \mathrm{~mL}$ acetone, was added to copper(II) acetate tetrahydrate $(0.8 \mathrm{~g}, 4 \mathrm{mmol})$ in $25 \mathrm{~mL} 40 \%$ methanol. The precipitated solids were washed with $40 \%$ methanol and acetone and dried over silica gel. Similar procedure was used for preparation of the other copper(II) complexes.

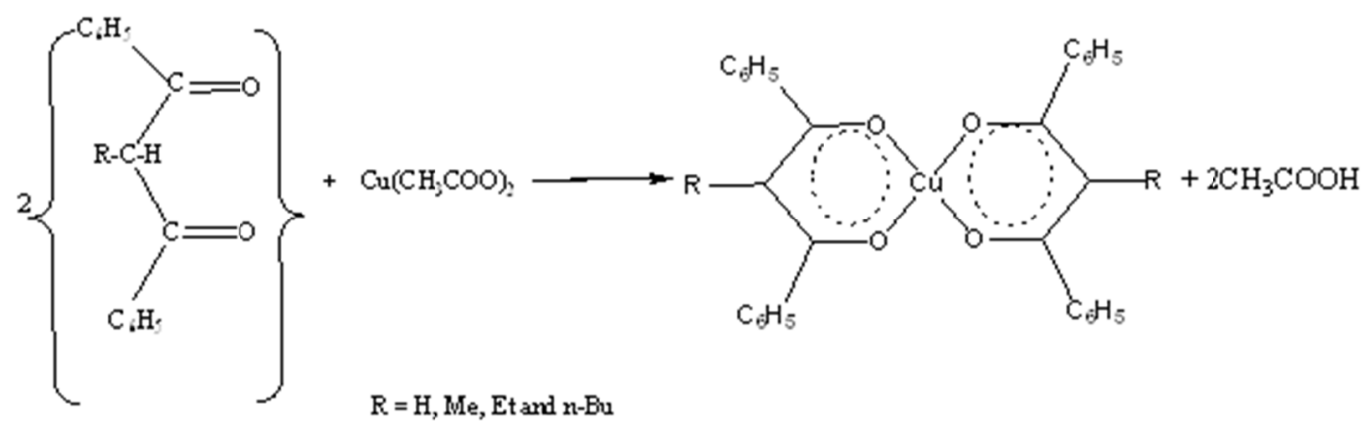

Equation 1. Preparation of copper(II) complex

\subsubsection{Synthesis of $\mathrm{Cu}(\mathrm{Me}-\mathrm{dbm})_{2}$ bipy}

Solid $\mathrm{Cu}(\mathrm{Me}-\mathrm{dbm})_{2}(0.3 \mathrm{~g}, 0.556 \mathrm{mmol})$ was added pinchwise to solution of 2,2'-bipyridine $(0.286 \mathrm{~g}, 1.833$ $\mathrm{mmol}$ ) in $15 \mathrm{~mL}$ chloroform. This mixture was stirred for 30minutes and the precipitates formed were filtered and washed with chloroform.

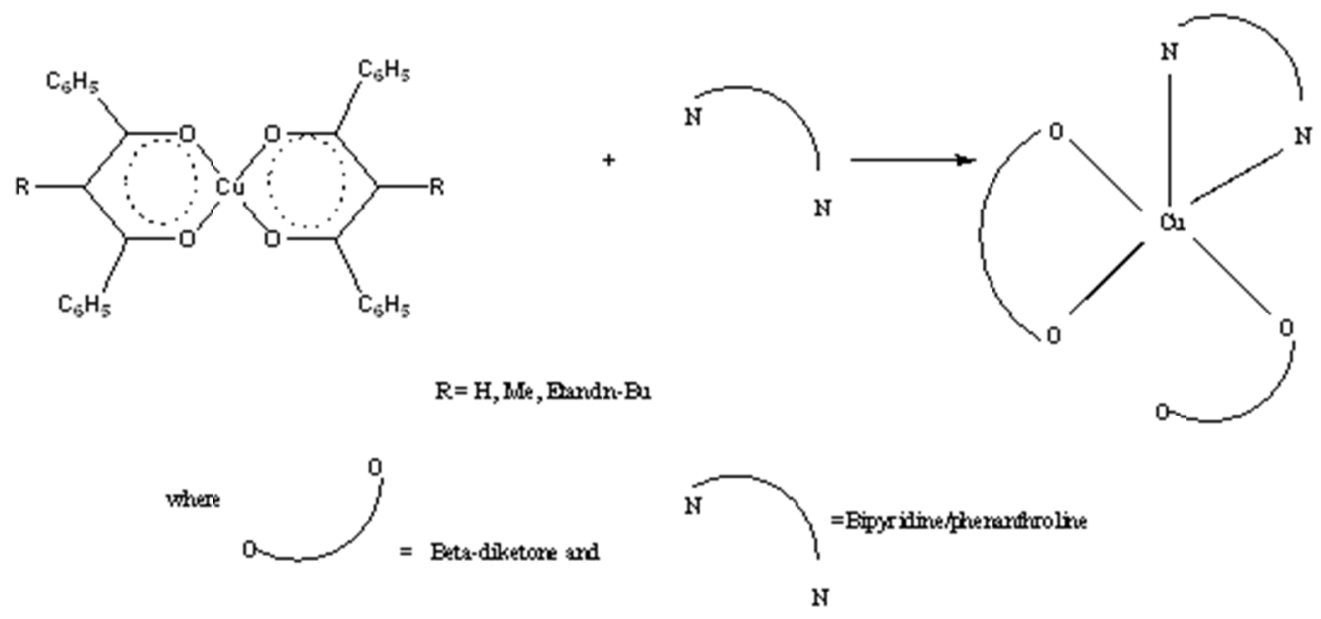

Equation 2. Preparation of copper(II) adduct

\subsection{Physical Measurements}

Elemental analyses for $\mathrm{C}, \mathrm{H}, \mathrm{N}$ were determined at Department of Chemistry, Loughborough University, UK. The $\%$ metal in the copper(II) complexes and adducts was determined titrimetrically with EDTA. The molar conductivities of the soluble compounds in nitromethane at room temperature were determined using Digital conductivity meter (Labtech).

The solution spectra of the compounds in methanol and chloroform were recorded on a Unicam UV-Visible Spectrophotometer using $1 \mathrm{~cm}$ glass cell. The reflectance spectra of the copper(II) compounds were recorded on a Perkin-Elmer Lambda 950 UV/VIS spectrophotometer at the Department of Chemical Engineering, Faculty of 
Technology, Addis Ababa University, Ethiopia using calcium carbonate as reference. The infrared spectra of the compounds, as pressed $\mathrm{KBr}$ disc, were recorded on Perkin-Elmer Spectrophotometer BX FT-IR.

\subsection{Computational Methods}

Complete geometrical optimisation without symmetry constraint was performed using DFT (Density Functional Theory) with Becke's three parameter exchange functional, along with the Lee-Yang-Parr correlation functional and with LANL2DZ basis set. All calculations were done with Spartan '06 V112 (Shao et al., 2006). The vibrational wavenumbers were calculated using the $\mathrm{PM} 3$ method and a $\mathrm{C} 1$ point group. The positive value of all the calculated wavenumbers indicates the stability of the optimised geometry.

\section{Results and Discussion}

The analytical and the physical data are shown in Table 1. Different shades of green colour were observed for all the copper(II) compounds. The Microanalytical data, as depicted in Table 2, shows that the elemental analyses are consistent with the proposed stoichiometry.

The prepared 2-substituted-1,3-diphenyl-1,3-propanedionato copper(II) complexes have moments in the range 1.75-2.00 B.M. An increase was observed on substituting the 2-position of $\mathrm{Cu}(\mathrm{dbm})_{2}$ with alkyl groups except $\mathrm{Cu}(\mathrm{n}-\mathrm{Bu}-\mathrm{dbm})_{2}$ with decreased moment. The observed magnetic moments of the synthesised 2,2'-bipyridine and 1,10-phenanthroline adducts of 2-substituted-1,3-diphenyl-1,3-propanedionato copper(II) complexes are in the range 1.95-2.10 B.M. This shows that they are magnetically dilute compounds and that there is no intermolecular magnetic interaction. An increase in magnetic moments was observed in all the adducts as compared with the appropriate parent complexes.

Table 1. Analytical and physical data of Copper(II) complexes of 2-substituted-1,3-diphenyl-1,3-propanedione and their adducts

\begin{tabular}{llllll}
\hline Formula & MM & Colour & M.Pt $\left({ }^{\circ} \mathrm{C}\right)$ & Yield $(\%)$ & $\mu$ eff $(\mathrm{B} . \mathrm{M})$ \\
\hline $\mathrm{Cu}(\mathrm{dbm})_{2}$ & 510.00 & Y. green & $300-302$ & 16.52 & 1.75 \\
$\mathrm{Cu}(\mathrm{dbm})_{2}$ bipy & 666.20 & D. green & $290-292$ & 15.50 & 2.04 \\
{$[\mathrm{Cu}(\mathrm{dbm})(\mathrm{Phen})](\mathrm{dbm})$} & 690.22 & Y. Green & $235-237$ & 62.42 & 1.95 \\
$\mathrm{Cu}(\mathrm{Me}-\mathrm{dbm})_{2}$ & 538.08 & Y. green & 203 & 20.4 & 1.78 \\
$\mathrm{Cu}(\mathrm{Me}-\mathrm{dbm})_{2}$ bipy & 694.26 & D. green & $290-292$ & 55.69 & 2.10 \\
{$[\mathrm{Cu}(\mathrm{Me}-\mathrm{dbm})($ Phen $)](\mathrm{Me}-\mathrm{dbm})$} & 736.30 & D. green & $283-285$ & 64.23 & 2.08 \\
$\mathrm{Cu}(\mathrm{Et}-\mathrm{dbm})_{2}$ & 566.14 & Y. green & $306-308$ & 57.03 & 2.00 \\
$\mathrm{Cu}(\mathrm{Et}-\mathrm{dbm})_{2}$ bipy & 722.32 & Green & $319-321$ & 30.86 & 2.06 \\
$\mathrm{Cu}(\mathrm{Et}-\mathrm{dbm})_{2}$ phen & 746.34 & Y. Green & $314-316$ & 24.2 & 2.10 \\
$\mathrm{Cu}(\mathrm{n}-\mathrm{Bu}-\mathrm{dbm})_{2}$ & 622.26 & Y. green & $317-319$ & 65.58 & 1.97 \\
$\mathrm{Cu}(\mathrm{n}-\mathrm{Bu}-\mathrm{dbm})_{2}$ bipy & 778.44 & B. green & $220-222$ & 42.89 & 2.10 \\
$\mathrm{Cu}(\mathrm{n}-\mathrm{Bu}-\mathrm{dbm})_{2}$ phen & 802.46 & B. green & $329-331$ & 45.96 & 2.10 \\
\hline
\end{tabular}

$\mathrm{D}=$ dark, $\mathrm{Y}=$ yellowish, $\mathrm{G}=$ greenish, $\mathrm{B}=$ bright.

The molar conductivities of these complexes were very low with $\Lambda_{\mathrm{m}}$ values of 4.2-29.7 $\mathrm{ohm}^{-1} \mathrm{~cm}^{2} \mathrm{~mole}^{-1}$, which suggests that they are non-electrolytes. Similarly, the molar conductivities of the $\mathrm{Cu}(\mathrm{R}-\mathrm{dbm})_{2}$ adducts indicate that they are non-electrolytes except $[\mathrm{Cu}(\mathrm{dbm})(\mathrm{phen})](\mathrm{dbm})$ and $[\mathrm{Cu}(\mathrm{Me}-\mathrm{dbm})(\mathrm{phen})](\mathrm{Me}-\mathrm{dbm})$, which are 1:1 electrolytes with an outer sphere anion as reflected in the $\Lambda_{\mathrm{m}}$ values of $82-84 \mathrm{ohm}^{-1} \mathrm{~cm}^{2} \mathrm{~mole}^{-1}$.

The carbonyl and carbon-carbon double bonds have less double bond character and more single bond character in the conjugated ring, which accounted for the large frequency shifts usually observed. Studies have revealed that three factors determine the position of the perturbed carbonyl band in the spectrum of a given chelate: the masses of the groups attached at the ends of the ligand molecule to the carbonyl groups; interaction of the carbonyl with neighbouring $\pi$ or d-orbitals and the relative electron density of the $\sigma$ bond. Moreover, the comparison of the infrared spectra taken at low temperature with those at room temperature shows that there is a sharpening up of the bands in the low temperature spectrum owing to the decreased population of the higher 
vibrational states of the molecule (Fackler et al., 1968).

In the complexes studied, the frequencies of the asymmetric $\mathrm{C}=\mathrm{O}$ and $\mathrm{C}=\mathrm{C}$ stretching vibrations were lowered from their free ligand values (Table 3). The $v_{\mathrm{as}}(\mathrm{C}=\mathrm{O})+v_{\mathrm{as}}(\mathrm{C}=\mathrm{C})$ vibrations of the copper(II) complexes occurred as multiple bands in the $1514-1653 \mathrm{~cm}^{-1}$ region. Single band of $v_{\mathrm{s}}(\mathrm{C}-\mathrm{O})+\delta \mathrm{C}-\mathrm{H}$ were observed in $\mathrm{Cu}(\mathrm{dbm})_{2}$ while $\mathrm{Cu}(\mathrm{Me}-\mathrm{dbm})_{2}, \mathrm{Cu}(\mathrm{Et}-\mathrm{dbm})_{2}$ and $\mathrm{Cu}(\mathrm{n}-\mathrm{Bu}-\mathrm{dbm})_{2}$ had double bands. Upon adduct formation, hypsochromic shifts of the $v_{\text {as }}(\mathrm{C}=\mathrm{O})+v_{\mathrm{as}}(\mathrm{C}=\mathrm{C})$ in all the adducts relative to the parent complexes were observed except $\mathrm{Cu}(\mathrm{Me}-\mathrm{dbm})_{2}$ bipy, $\mathrm{Cu}(\mathrm{Me}-\mathrm{dbm})_{2}$ phen, and $\mathrm{Cu}(\mathrm{Et}-\mathrm{dbm})_{2}$ phen which had bathochromic shifts. The observed shifts can be used to predict the type of bonds in the adducts (Holtzclaw \& Collman, 1957; Tanaka et al., 1969). The hypsochromic shifts probably indicate stronger $\mathrm{Cu}-\mathrm{N}$ and $\mathrm{C}-\mathrm{O}$ bonds and weaker $\mathrm{Cu}-\mathrm{O}$ bonds while the reverse is applicable for bathochromic shifts. The symmetric and asymmetric methyl bending vibrations of the adducts appeared with varying shifts as compared with the complexes. $\mathrm{CH}$ deformation bands of 2,2'-bipyridine were observed as strong bands in the $745-778 \mathrm{~cm}^{-1}$ region while the phenanthroline adducts bands were observed around 717-722 $\mathrm{cm}^{-1}$ and $843-856 \mathrm{~cm}^{-1}$ region. Coupled $\mathrm{Cu}-\mathrm{O}$ and $\mathrm{Cu}-\mathrm{N}$ stretching vibrational modes occurred in the range $420-696 \mathrm{~cm}^{-1}$ in the 2,2'-bipyridine and 1,10- phenanthroline adducts (Patel \& Woods, 1990b).

Table 2. Microanalytical data of Copper(II) complexes of 2-substituted-1,3-diphenyl-1,3-propanedione and their adducts

\begin{tabular}{llrrrl}
\hline \multirow{2}{*}{} & \multirow{2}{*}{ Compound } & \multicolumn{4}{c}{$\%$ Calculated (Observed) } \\
\cline { 3 - 6 } & & $\mathrm{C}$ & $\mathrm{H}$ & $\mathrm{N}$ & \multicolumn{1}{c}{$\mathrm{M}$} \\
\hline 1. & $\mathrm{Cu}(\mathrm{dbm})_{2}$ & $70.64(70.51)$ & $4.36(4.37)$ & - & $12.45(12.83)$ \\
2. & $\mathrm{Cu}(\mathrm{dbm})_{2}$ bipy & $72.11(72.28)$ & $4.55(4.72)$ & $4.20(4.18)$ & $9.53(9.73)$ \\
3. & {$[\mathrm{Cu}(\mathrm{dbm})($ phen $)](\mathrm{dbm})$} & $73.08(73.12)$ & $4.39(4.46)$ & $4.06(4.02)$ & $9.20(8.97)$ \\
4. & $\mathrm{Cu}(\mathrm{Me}-\mathrm{dbm})_{2}$ & $71.42(71.52)$ & $4.88(5.07)$ & - & $11.80(11.96)$ \\
5. & $\mathrm{Cu}(\mathrm{Me}-\mathrm{dbm})_{2}$ bipy & $72.66(72.59)$ & $4.95(5.29)$ & $4.03(3.92)$ & $9.15(8.81)$ \\
6. & {$[\mathrm{Cu}(\mathrm{Me}-\mathrm{dbm})($ phen $)](\mathrm{Me}-\mathrm{dbm})$} & $71.77(71.52)$ & $4.94(4.89)$ & $3.80(4.05)$ & $8.62(8.32)$ \\
7. & $\mathrm{Cu}(\mathrm{Et}-\mathrm{dbm})_{2}$ & $72.13(71.90)$ & $5.35(5.09)$ & - & $11.22(11.45)$ \\
8. & $\mathrm{Cu}(\mathrm{Et}-\mathrm{dbm})_{2}$ bipy & $73.16(73.09)$ & $5.31(5.51)$ & $3.88(4.09)$ & $8.79(8.98)$ \\
9. & $\mathrm{Cu}(\mathrm{Et}-\mathrm{dbm})_{2}$ phen & $74.02(73.88)$ & $5.14(4.90)$ & $3.75(3.86)$ & $8.51(8.64)$ \\
10. & $\mathrm{Cu}(\mathrm{n}-\mathrm{Bu}-\mathrm{dbm})_{2}$ & $73.34(73.18)$ & $6.17(5.92)$ & - & $10.20(10.59)$ \\
11. & $\mathrm{Cu}(\mathrm{n}-\mathrm{Bu}-\mathrm{dbm})_{2}$ bipy & $74.06(73.10)$ & $5.97(6.15)$ & $3.60(3.81)$ & $8.16(7.84)$ \\
12. & $\mathrm{Cu}(\mathrm{n}-\mathrm{Bu}-\mathrm{dbm})_{2}$ phen & $74.83(75.04)$ & $5.79(5.60)$ & $3.49(3.52)$ & $7.91(8.21)$ \\
\hline
\end{tabular}

The solution spectra of the copper(II) complexes were studied in chloroform and methanol. The assignments of the bands have been made with the help of literature on similar compounds (Fackler et al., 1968; Patel \& Woods, 1990b, 1990c). Hypsochromic shift of the $\pi_{3}-\pi^{*}{ }_{4}$ band was observed in $\mathrm{Cu}(\mathrm{Et}-\mathrm{dbm})_{2}$ as compared with $\mathrm{Cu}(\mathrm{dbm})_{2}$ in chloroform. $\mathrm{Cu}(\mathrm{Me}-\mathrm{dbm})_{2}$ had bathochromic shift while $\mathrm{Cu}(\mathrm{n}-\mathrm{Bu}-\mathrm{dbm})_{2}$ had no shift. Coordinating solvents have been found to have a particular dramatic effect on the ligand field spectra of copper(II) compounds (Patel \& Woods, 1990b). As a result of this, when there is a higher frequency shift in the ligand field spectra band of the copper compounds in coordinating solvents relative to non-coordinating (chloroform), it indicates a probable square pyramidal structure. A probable four coordinate square planar structure is observed when there is lower frequency shift in coordinating solvent relative to non-coordinating. For six-coordinate octahedral geometry, the band position remains unchanged in both coordinating and non-coordinating solvents. Thus, the various synthesised $\mathrm{Cu}(\mathrm{R}-\mathrm{dbm})_{2}$ have probable, four-coordinate, square planar geometry due to their lower frequency shifts in methanol relative to chloroform. Copper(II) complexes with square planar stereochemistry commonly exhibit a broad structured band between 13,000 to $20,000 \mathrm{~cm}^{-1}$. They have absorption that shows little structure between 18,000 to $21,000 \mathrm{~cm}^{-1}$ and no electronic absorption below $10,000 \mathrm{~cm}^{-1}$ (Lever, 1986). In the synthesised complexes, the little structure absorption was observed between $18,051-18,087 \mathrm{~cm}^{-1}$ in chloroform, which also shows that the various synthesised $\mathrm{Cu}(\mathrm{R}-\mathrm{dbm})_{2}$ have probable four-coordinate, square planar geometry. 
Table 3. Relevant Infrared Spectra bands $\left(\mathrm{cm}^{-1}\right)$ of 1,3-diphenyl-1,3-propanedione, the Copper(II) complexes and their adducts

\begin{tabular}{|c|c|c|c|c|}
\hline Formula & $\mathrm{C}=\mathrm{O}, \mathrm{C}=\mathrm{C}$ & $v_{s}(\mathrm{C}-\mathrm{O})+\delta \mathrm{C}-\mathrm{H}$ & $\begin{array}{c}\delta_{\mathrm{as}}\left(\mathrm{CH}_{3}\right)+ \\
\delta_{\mathrm{s}}\left(\mathrm{CH}_{3}\right)\end{array}$ & $\begin{array}{c}\gamma(\mathrm{C}-\mathrm{H}) \\
\text { Phen/bipy }\end{array}$ \\
\hline $\mathrm{dbmH}$ & $1598 b, 1540 b$ & $1466 b$ & - & - \\
\hline $\mathrm{Cu}(\mathrm{dbm})_{2}$ & $1593 \mathrm{~s}, 1545 \mathrm{~b}, 1526 \mathrm{~b}$ & $1484 \mathrm{~m}$ & - & - \\
\hline $\mathrm{Cu}(\mathrm{dbm})_{2}$ bipy & $1618 \mathrm{w}, 1593 \mathrm{~s}, 1515 \mathrm{~s}$ & $1484 m$ & - & $745 \mathrm{~s}$ \\
\hline$[\mathrm{Cu}(\mathrm{dbm})(\mathrm{phen})](\mathrm{dbm})$ & $1624 \mathrm{w}, 1594 \mathrm{~m}, 1551 \mathrm{~s}$ & $1478 \mathrm{~m}, 1451 \mathrm{~m}$ & - & $843 \mathrm{~m}, 721 \mathrm{~s}$ \\
\hline Me-dbmH & $1689 \mathrm{~m}, 1664 \mathrm{~m}, 1595 \mathrm{~m}$ & $1450 \mathrm{~s}$ & $1346 \mathrm{~s}$ & \\
\hline $\mathrm{Cu}(\mathrm{Me}-\mathrm{dbm})_{2}$ & $1653 \mathrm{vw}, 1582 \mathrm{~m}, 1514 \mathrm{~s}$ & $1498 \mathrm{~m}, 1471 \mathrm{w}$ & $1418 \mathrm{~m}, 1370 \mathrm{~m}$ & \\
\hline $\mathrm{Cu}(\mathrm{Me}-\mathrm{dbm})_{2}$ bipy & $1594 \mathrm{~s}, 1546 \mathrm{~m}, 1525 \mathrm{~m}$ & $1484 \mathrm{~m}, 1455 \mathrm{~m}$ & $1400 \mathrm{~s}$ & $764 w$ \\
\hline $\begin{array}{c}{[\mathrm{Cu}(\mathrm{Me}-\mathrm{dbm})(\mathrm{phen})]} \\
(\mathrm{Me}-\mathrm{dbm})\end{array}$ & $1630 \mathrm{w}, 1587 \mathrm{w}, 1518 \mathrm{~s}$ & & $1343 m$ & $852 \mathrm{~s}, 722 \mathrm{~s}$ \\
\hline Et-dbmH & $1687 \mathrm{vs}, 1665 \mathrm{~s}, 1697 \mathrm{vs}$ & $1466 \mathrm{~b}, 1449 \mathrm{~m}$ & $1356 \mathrm{~s}$ & \\
\hline $\mathrm{Cu}(\mathrm{Et}-\mathrm{dbm})_{2}$ & $1595 \mathrm{~s}, 1542 \mathrm{~m}, 1524 \mathrm{~m}$ & $1475 \mathrm{~s}, 1457 \mathrm{~m}$ & $1402 \mathrm{vs}$ & \\
\hline $\mathrm{Cu}(\mathrm{Et}-\mathrm{dbm})_{2}$ phen & $1587 \mathrm{~m}, 1546 \mathrm{~m}, 1516 \mathrm{vs}$ & $1456 \mathrm{w}, 1424 \mathrm{vs}, 1401 \mathrm{w}$ & $854 \mathrm{vs}$ & $721 \mathrm{vs}$ \\
\hline n-Bu-dbmH & $1693 \mathrm{~s}, 1667 \mathrm{~s}, 1596 \mathrm{~m}$ & $1447 \mathrm{~s}$ & $1380 \mathrm{vw}, 1348 \mathrm{~m}$ & \\
\hline $\mathrm{Cu}(\mathrm{n}-\mathrm{Bu}-\mathrm{dbm})_{2}$ & $1598 \mathrm{~s}, 1532 \mathrm{~b}$ & $1482 \mathrm{~m}, 1456 \mathrm{~m}$ & $1398 \mathrm{vs}$ & \\
\hline $\mathrm{Cu}(\mathrm{n}-\mathrm{Bu}-\mathrm{dbm})_{2}$ bipy & $1606 \mathrm{~s}, 1572 \mathrm{~m}, 1551 \mathrm{w}$ & $1470 \mathrm{~s}, 1442 \mathrm{vs}, 1382 \mathrm{~m}$ & & 774vs \\
\hline $\mathrm{Cu}(\mathrm{n}-\mathrm{Bu}-\mathrm{dbm})_{2}$ phen & $1627 \mathrm{w}, 1584 \mathrm{~m}, 1514 \mathrm{~s}$ & $1496 \mathrm{w}, 1426 \mathrm{vs}, 1373 \mathrm{w}$ & & $856 \mathrm{vs}, 718 \mathrm{vs}$ \\
\hline
\end{tabular}

$\mathrm{B}=$ broad, $\mathrm{s}=$ strong, $\mathrm{v}=$ very, $\mathrm{w}=$ weak, $\mathrm{m}=$ medium.

In a study, the visible bands shifted to higher frequencies on replacement of hydrogen by alkyl groups and the magnitude of the shift was about the same in all the solvents. This was attributed to the inductive effect of the alkyl groups leading to a higher ligand field. It was also detected that lengthening of the alkyl side chain produced no further change in the formation constants (Graddon \& Schulz, 1965). Transitions in Copper(II) of $\beta$-diketonates with absorption at energies higher than $24,000 \mathrm{~cm}^{-1}$ originate from charge transfer from $\beta$-diketones ion to the metal (Melnik et al., 1996; Gorbenko et al., 1997). In the prepared complexes, high-energy absorption was observed at $27,855 \mathrm{~cm}^{-1}$ in $\mathrm{Cu}(\mathrm{dbm})_{2}$.

The tentative assignment of the reflectance spectra of the ligands (R-dbmH), copper(II) complexes and their adducts in calcium carbonate are presented in Table 5. The visible spectra of all the complexes studied displayed three bands in this region with varying $\lambda_{\max }$ between $12,121-21,505 \mathrm{~cm}^{-1}$, which is consistent with square planar geometry for copper(II) complexes. The spectra of the $\mathrm{Cu}(\mathrm{R}-\mathrm{dbm})_{2}$ adducts displayed single bands in the visible region between $13,553-14,698 \mathrm{~cm}^{-1}$. This is also consistent with square pyramidal geometry for copper(II) compounds (Odunola et al., 2003) except [Cu(dbm)(Phen)](dbm) and [Cu(Me-dbm)(Phen)](Me-dbm) with little structure absorption at $18,149-21,978 \mathrm{~cm}^{-1}$ which corresponded with square planar structures (Lever, 1986). In the synthesised complexes, $\pi_{3}-\pi_{4} *$ transitions were observed in the $31,153-33,445 \mathrm{~cm}^{-1}$ region. Splitting of this band was not observed in any of the prepared complexes. Bands in the $40,000-44,843 \mathrm{~cm}^{-1}$ regions have been assigned as benzenoid $/ \sigma_{\mathrm{L}}-3 \mathrm{~d}_{\mathrm{xy}}$ transitions (Johnson \& Thornton, 1975). The ultraviolet region of the solid reflectance spectra of the adducts showed hypsochromic shift of the $\pi_{3}-\pi_{4} *$ transition upon adduct formation. In the adducts, $\pi_{3}-\pi_{4} *$ transition appeared as single bands at $32,154-35,971 \mathrm{~cm}^{-1}$ region except $\mathrm{Cu}(\text { Et-dbm })_{2}$ bipy which had an additional band. 
Table 4. The electronic solution spectra of 2-substituted-1,3-diphenyl-1,3-propanedione Copper(II) complexes and their adducts

\begin{tabular}{|c|c|c|c|c|}
\hline \multirow{2}{*}{ Emperical Formula } & \multicolumn{2}{|c|}{$\pi_{3}-\pi_{4} *\left(\mathrm{~cm}^{-1}\right)$} & \multicolumn{2}{|c|}{ d-d } \\
\hline & $\mathrm{CHCl}_{3}$ & $\mathrm{CH}_{3} \mathrm{OH}$ & $\mathrm{CHCl}_{3}$ & $\mathrm{CH}_{3} \mathrm{OH}$ \\
\hline $\mathrm{dbmH}$ & $34,483(20567)$ & $34,364(23114)$ & & \\
\hline \multirow{2}{*}{$\mathrm{Cu}(\mathrm{dbm})_{2}$} & $34,722 *$ & - & $18,051^{*}$ & - \\
\hline & $34,014(45546)$ & & $15,337(7735)$ & \\
\hline $\mathrm{Cu}(\mathrm{dbm})_{2}$ bipy & $33,445(?)$ & $32,895(?)$ & - & $13,947(?)$ \\
\hline \multirow[t]{2}{*}[\mathrm{Cu}(\mathrm{dbm})(\mathrm{phen})]{$(\mathrm{dbm})$} & $34,014^{*}$ & $34,014(24354)$ & $20,325^{*}$ & $16,340(116)$ \\
\hline & & & $13,966(225)$ & \\
\hline Me-dbmH & $34,247(5282)$ & - & & \\
\hline \multirow[t]{2}{*}{$\mathrm{Cu}(\mathrm{Me}-\mathrm{dbm})_{2}$} & $34,014 *$ & $35,971(?)$ & $15,991(?)$ & $15,649(?)$ \\
\hline & & $34,247(?)$ & & $14,164(?)$ \\
\hline \multirow[t]{2}{*}{$\mathrm{Cu}(\mathrm{Me}-\mathrm{dbm})_{2}$ bipy } & $33,333(7462)$ & $33,113(11609)$ & $16,181(59)$ & $16,831(62)$ \\
\hline & & & $12,531(555)$ & \\
\hline \multirow[t]{2}{*}[\mathrm{Cu}(\mathrm{Me}-\mathrm{dbm})(\mathrm{phen})]{$(\mathrm{Me}-\mathrm{dbm})$} & $34,114(37393)$ & $34,483(57112)$ & $20,492(405)$ & $16,129(234)$ \\
\hline & & & 13,966 & \\
\hline Et-dbmH & $32,259(20203)$ & $34,602(6951)$ & & \\
\hline $\mathrm{Cu}(\text { Et-dbm })_{2}$ & $34,965(?)$ & - & & \\
\hline \multirow[t]{2}{*}{$\mathrm{Cu}(\mathrm{Et}-\mathrm{dbm})_{2}$ bipy } & $34,602(?)$ & $33,445(?)$ & $14,970(?)$ & $15,966(?)$ \\
\hline & & $32,258(?)$ & & \\
\hline $\mathrm{Cu}(\text { Et-dbm })_{2}$ phen & $34,722 *$ & $34,843(?)$ & - & $15,314(?)$ \\
\hline n-Bu-dbmH & $35,211(?)$ & $35,088(?)$ & & \\
\hline \multirow[t]{2}{*}{$\mathrm{Cu}(\mathrm{n}-\mathrm{Bu}-\mathrm{dbm})_{2}$} & $34,722^{*}$ & $34,965^{*}$ & $18,087^{*}$ & $17,422(?)$ \\
\hline & & & $14,903(?)$ & \\
\hline $\mathrm{Cu}(\mathrm{n}-\mathrm{Bu}-\mathrm{dbm})_{2}$ bipy & $33,557(?)$ & $33,223(?)$ & $15,015(?)$ & $15,947(?)$ \\
\hline $\mathrm{Cu}(\mathrm{n}-\mathrm{Bu}-\mathrm{dbm})_{2}$ phen & $33,784(?)$ & $34,364(?)$ & $15,823(?)$ & $15,928(?)$ \\
\hline
\end{tabular}

(?) Compounds are partially soluble in the solvent. 
Table 5. The electronic solid reflectance spectra of 2-substituted-1,3-diphenyl-1,3-propanedione, Copper(II) complex and its adducts

\begin{tabular}{|c|c|c|}
\hline Emperical Formula & $\pi_{3}-\pi_{4} *\left(\mathrm{~cm}^{-1}\right)$ & d-d \\
\hline $\mathrm{dbmH}$ & 35,211 & - \\
\hline $\mathrm{Cu}(\mathrm{dbm})_{2}$ & 33,445 & $19,493,16,892,12,121$ \\
\hline $\mathrm{Cu}(\mathrm{dbm})_{2}$ bipy & 35,842 & 14,048 \\
\hline$[\mathrm{Cu}(\mathrm{dbm})($ Phen $)](\mathrm{dbm})$ & 33,557 & $21,322^{*}, 18,149,12,092$ \\
\hline Me-dbmH & 34,398 & - \\
\hline $\mathrm{Cu}(\mathrm{Me}-\mathrm{dbm})_{2}$ & 33,014 & $18,360 * 15,198,12,170$ \\
\hline $\mathrm{Cu}(\mathrm{Me}-\mathrm{dbm})_{2}$ bipy & 33,557 & 14,305 \\
\hline$[\mathrm{Cu}(\mathrm{Me}-\mathrm{dbm})(\mathrm{Phen})](\mathrm{Me}-\mathrm{dbm})$ & 34,965 & $21,142^{*}, 18,282,12,048$ \\
\hline Et-dbmH & $35,088,33,003$ & \\
\hline $\mathrm{Cu}(\mathrm{Et}-\mathrm{dbm})_{2}$ & 31,153 & $21,505,19,455,12,195$ \\
\hline $\mathrm{Cu}(\mathrm{Et}-\mathrm{dbm})_{2}$ bipy & $35,971,32,154$ & $13,692,14,531$ \\
\hline $\mathrm{Cu}(\mathrm{Et}-\mathrm{dbm})_{2}$ phen & 34,014 & 14,493 \\
\hline n-Bu-dbmH & 35,971 & \\
\hline $\mathrm{Cu}(\mathrm{n}-\mathrm{Bu}-\mathrm{dbm})_{2}$ & 33,113 & $19,531,17,123,12,225$ \\
\hline $\mathrm{Cu}(\mathrm{n}-\mathrm{Bu}-\mathrm{dbm})_{2}$ bipy & 34,843 & 14,455 \\
\hline $\mathrm{Cu}(\mathrm{n}-\mathrm{Bu}-\mathrm{dbm})_{2}$ phen & 34,602 & 13,692 \\
\hline
\end{tabular}
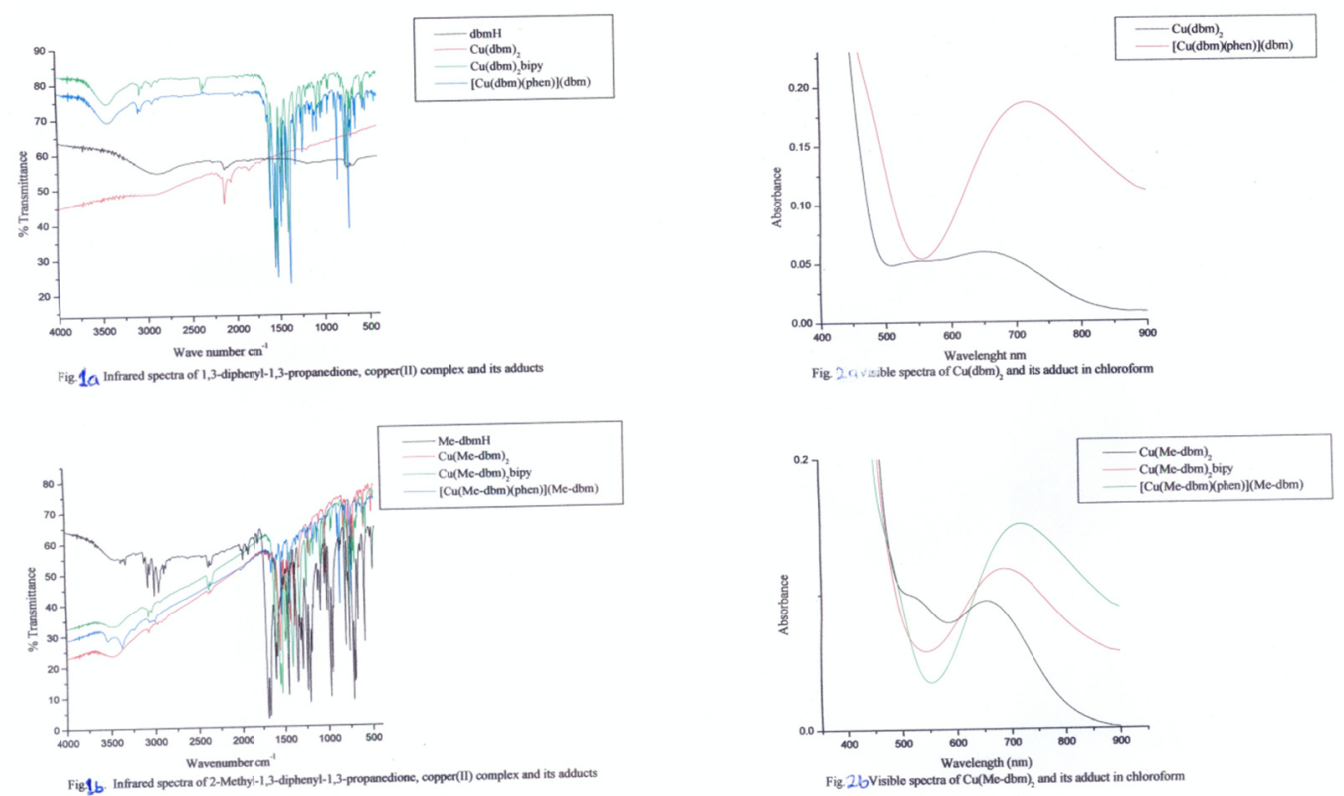

Figure 1. a) Infrared spectra of 1,3-diphenyl-1,3-propancedione, copper(II) complex and its adducts b) Infrared spectra of 2-Methyl-1,3-diphenyl-1,3-propancedione, copper(II) complex and its adducts Figure 2. a) Visible spectra of $\mathrm{Cu}(\mathrm{dbm})_{2}$ and its adduct in chloroform b) Visible spectra of $\mathrm{Cu}(\mathrm{Me}-\mathrm{dbm})_{2}$ and its adduct in chloroform 


\section{Computational Studies}

\subsection{Geometry and Structural Data}

Density Functional Theory at B3LYP/LANL2DZ was used for geometry optimisation and electronic structure determination (Karakas \& Sayin, 2013; Malecki et al., 2010). The optimised geometry of the $\mathrm{Cu}(\mathrm{Me}-\mathrm{dbm})_{2}$ bipy is shown in Figures 3(a) and (b). Table 6 shows the selected calculated bond distances, angles, of the modeled compound and the experimental X-ray crystallographic data (Zheng et al., 1991) of a five-coordinated copper(II) complex of 2,2'-bipyridine. The optimised bond distances at both semi-empirical PM3 and B3LYP levels are comparable with the corresponding values obtained from the X-ray diffraction as can be seen in Table 6 (Zheng et al., 1991). The DFT calculated angles/bite angles for $\mathrm{O}(1)-\mathrm{Cu}-\mathrm{O}(2), \mathrm{O}(1)-\mathrm{Cu}-\mathrm{O}(3), \mathrm{O}(1)-\mathrm{Cu}-\mathrm{N}(2)$, $\mathrm{N}(1)-\mathrm{Cu}-\mathrm{N}(2)$ and $\mathrm{O}(2)-\mathrm{Cu}-\mathrm{N}(1)$ are $89.37^{\circ}, 87.97^{\circ}, 109.26^{\circ}, 77.7^{\circ}$, and $92.40^{\circ}$ respectively. The variation from the ideal value could be attributed to the distortion from the perfect square pyramidal structure around the Copper(II) ion of the compound. Figures 3(c) and 3(d) show the HOMO and LUMO orbitals of the Copper(II) compound. The HOMO is predominantly located on the $2,2^{\prime}$-Bipyridine moiety and the LUMO is essentially spread around the 2 units of 2-Methyl-1,3-diphenyl-1,3-propanedione. The B3LYP modeled molecular structure is five coordinate Copper(II) adduct and consists of 2 units of 2-Methyl-1,3-diphenyl-1,3-propanedione and one unit of 2,2'-Bipyridine. The coordinated environment around the Copper(II) is a distorted square pyramidal with three oxygen atoms of 2-Methyl-1,3-diphenyl-1,3-propanedione and two nitrogen atom of 2,2'-Bipyridine.

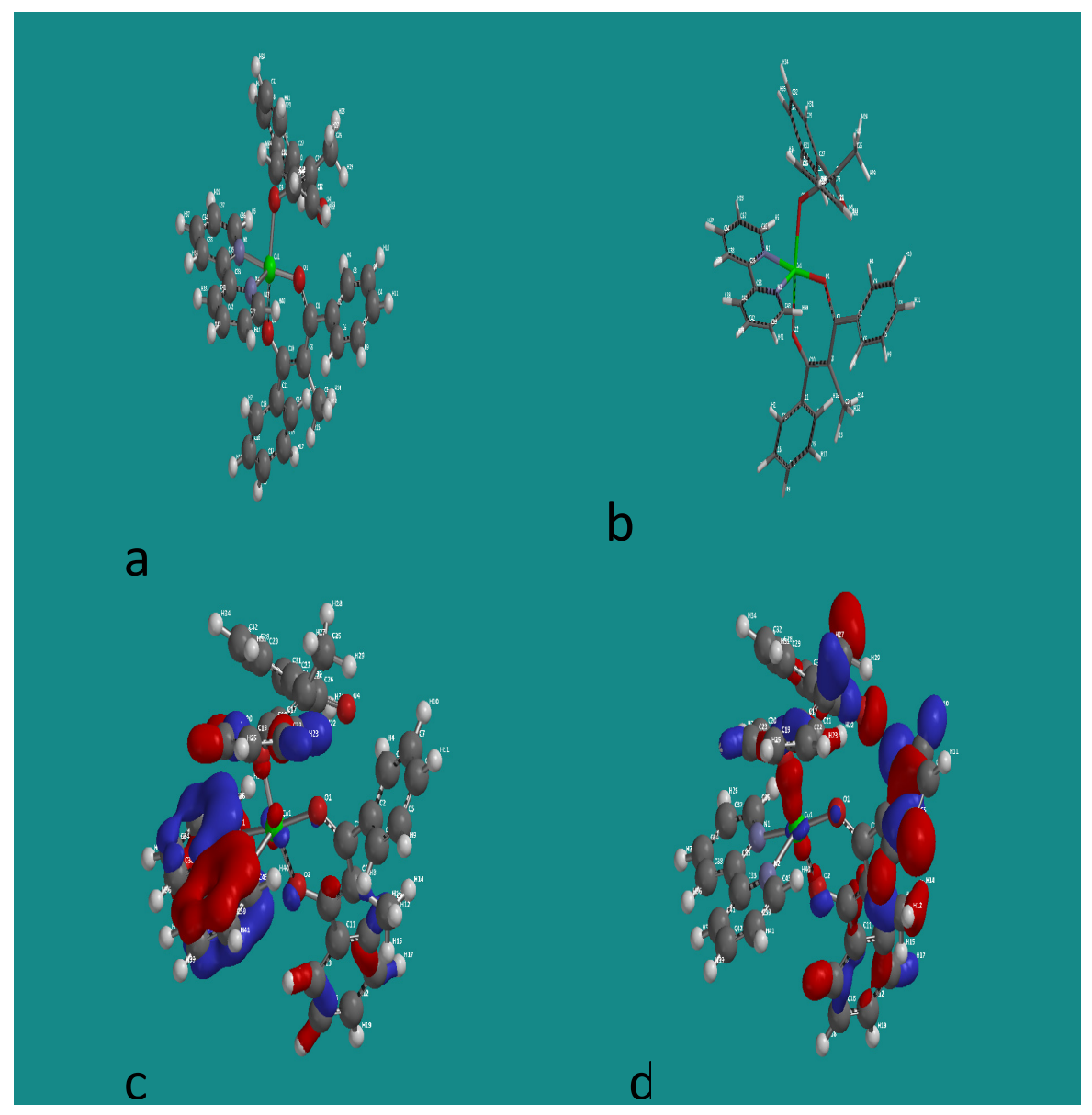

Figure 3. (a) FB3LYP Optimized structure of $\mathrm{Cu}(\mathrm{Me}-\mathrm{dbm})_{2}$ bipy; (b) Optimized structure of $\mathrm{Cu}(\mathrm{Me}-\mathrm{dbm})_{2}$ bipy (Tube form); (c) Lumo plot of $\mathrm{Cu}(\mathrm{Me}-\mathrm{dbm})_{2}$ bipy; (d) Homo plot of $\mathrm{Cu}(\mathrm{Me}-\mathrm{dbm})_{2}$ bipy

The molecular data from DFT calculation are summarized in Table 7. The energy gap between LUMO (lowest unoccupied molecular orbital) and HOMO (highest occupied molecular orbital) is $0.329 \mathrm{eV}$. The low energy gap indicates high reactivity (Fan et al., 2007; Herrag et al., 2010; Obot \& Obi-Egbedi, 2010; Obot et al., 2012). The dipole moment is 28.93 debye. The value of the dipole moment indicates that $\mathrm{Cu}(\mathrm{Me}-\mathrm{dbm})_{2}$ bipy is polar and has 
Table 6. Selected calculated bond distances, angles, of the modeled compounds and the experimental X-ray crystallographic data

\begin{tabular}{|c|c|c|c|}
\hline Numbering & PM3 & B3LYP/LANL2DZ & $\operatorname{Exp}^{a}$ \\
\hline $\mathrm{Cu}-\mathrm{O}_{1}$ & 1.853 & 1.902 & 1.935 \\
\hline $\mathrm{Cu}-\mathrm{O}_{2}$ & 1.866 & 1.958 & 1.920 \\
\hline $\mathrm{Cu}-\mathrm{O}_{3}$ & 1.859 & 1.961 & 2.204 \\
\hline $\mathrm{Cu}-\mathrm{N}_{1}$ & 1.881 & 2.015 & 1.983 \\
\hline $\mathrm{Cu}-\mathrm{N}_{2}$ & 1.978 & 2.269 & 1.991 \\
\hline $\mathrm{O}_{1}-\mathrm{C}_{1}$ & 1.299 & 1.326 & 1.274 \\
\hline $\mathrm{O}_{2}-\mathrm{C}_{10}$ & 1.307 & 1.304 & 1.260 \\
\hline $\mathrm{N}_{1}-\mathrm{C}_{35}$ & 1.383 & 1.360 & 1.356 \\
\hline $\mathrm{N}_{1}-\mathrm{C}_{36}$ & 1.368 & 1.348 & $1.335(8)$ \\
\hline $\mathrm{N}_{2}-\mathrm{C}_{33}$ & 1.384 & 1.357 & 1.341 \\
\hline $\mathrm{N}_{2}-\mathrm{C}_{43}$ & 1.367 & 1.346 & 1.336 \\
\hline $\mathrm{C}_{33}-\mathrm{C}_{35}$ & 1.483 & 1.485 & 1.478 \\
\hline $\mathrm{C}_{33}-\mathrm{C}_{41}$ & 1.399 & 1.403 & 1.373 \\
\hline $\mathrm{C}_{34}-\mathrm{C}_{38}$ & 1.393 & 1.397 & $1.36(1)$ \\
\hline $\mathrm{C}_{34}-\mathrm{C}_{37}$ & 1.389 & 1.398 & $1.36(1)$ \\
\hline $\mathrm{C}_{35}-\mathrm{C}_{38}$ & 1.399 & 1.403 & $1.36(1)$ \\
\hline $\mathrm{C}_{36}-\mathrm{C}_{37}$ & 1.396 & 1.395 & $1.38(1)$ \\
\hline $\mathrm{C}_{39}-\mathrm{C}_{43}$ & 1.395 & 1.398 & $1.37(1)$ \\
\hline $\mathrm{C}_{39}-\mathrm{C}_{42}$ & 1.388 & 1.398 & $1.37(1)$ \\
\hline $\mathrm{C}_{41}-\mathrm{C}_{42}$ & 1.393 & 1.398 & $1.38(1)$ \\
\hline $\mathrm{O}_{1}-\mathrm{Cu}-\mathrm{O}_{2}$ & 97.31 & 89.37 & 92.2 \\
\hline $\mathrm{O}_{1}-\mathrm{Cu}-\mathrm{O}_{3}$ & 89.77 & 87.97 & 93.3 \\
\hline $\mathrm{O}_{1}-\mathrm{Cu}-\mathrm{N}_{2}$ & 100.13 & 109.26 & 91.9 \\
\hline $\mathrm{O}_{1}-\mathrm{Cu}-\mathrm{N}_{1}$ & 167.76 & 1732.60 & 167.3 \\
\hline $\mathrm{O}_{2}-\mathrm{Cu}-\mathrm{N}_{1}$ & 86.28 & 92.40 & 92.2 \\
\hline $\mathrm{O}_{1}-\mathrm{C}_{1}-\mathrm{C}_{8}$ & 128.37 & 126.15 & 123.6 \\
\hline $\mathrm{O}_{2}-\mathrm{C}_{10}-\mathrm{C}_{8}$ & 127.54 & 123.64 & 127.9 \\
\hline $\mathrm{N}_{1}-\mathrm{Cu}-\mathrm{N}_{2}$ & 90.78 & 77.70 & 81.2 \\
\hline $\mathrm{N}_{1}-\mathrm{Cu}-\mathrm{O}_{3}$ & 83.38 & 88.04 & 97.6 \\
\hline $\mathrm{N}_{2}-\mathrm{Cu}-\mathrm{O}_{3}$ & 96.91 & 102.57 & 92.8 \\
\hline $\mathrm{N}_{1}-\mathrm{C}_{36}-\mathrm{C}_{37}$ & 120.71 & 121.56 & 122.1 \\
\hline $\mathrm{N}_{1}-\mathrm{C}_{35}-\mathrm{C}_{33}$ & 117.53 & 116.99 & 114.2 \\
\hline $\mathrm{N}_{1}-\mathrm{C}_{35}-\mathrm{C}_{38}$ & 119.52 & 119.58 & 121.4 \\
\hline $\mathrm{N}_{2}-\mathrm{C}_{33}-\mathrm{C}_{41}$ & 120.74 & 120.78 & 121.7 \\
\hline $\mathrm{N}_{2}-\mathrm{C}_{33}-\mathrm{C}_{35}$ & 116.69 & 115.83 & 114.3 \\
\hline $\mathrm{C}_{1}-\mathrm{C}_{8}-\mathrm{C}_{10}$ & 119.72 & 119.99 & 123.8 \\
\hline $\mathrm{C}_{36}-\mathrm{N}_{1}-\mathrm{C}_{35}$ & 120.43 & 121.13 & 118.4 \\
\hline $\mathrm{C}_{43}-\mathrm{N}_{2}-\mathrm{C}_{33}$ & 118.65 & 120.11 & 119.0 \\
\hline $\mathrm{C}_{43}-\mathrm{N}_{2}-\mathrm{Cu}$ & 135.06 & 129.08 & 125.7 \\
\hline
\end{tabular}

a. Ref. (Sheela,Sampathkrishnan, Kumar, \& Muthu, 2013). 
high tendency to react with other charged compounds (Herrag et al., 2010). The modeled Copper(II) complex has 83 atoms, 234 normal modes of fundamental vibrations and possesses $\mathrm{C} 1$ point group. By using semi-empirical PM3 method, the vibrational frequencies of the modeled Copper(II) complex were calculated in the ground state. Calculated vibrational frequencies are scaled by a factor 0.974 , that was recommended by Scott and Radom (Scott \& Radom, 1996). Fourteen calculated vibrational frequencies are selected and reported in Table 8. Some of the calculated vibrational wavenumbers were found to agree quite well with the available experimental data. Discrepancy between calculated and experimental values could be due, in part, to anharmonicity and the tendency of the quantum chemical methods to overestimate the force constants at the exact equilibrium geometry (Sheela et al., 2013).

Table 7. The DFT Molecular parameters of $\mathrm{Cu}(\mathrm{Me}-\mathrm{dbm})_{2}$ bipy

$$
\begin{aligned}
& \mathrm{E}_{\text {LUMO }}(\mathrm{eV})-3.509866 \\
& \mathrm{E}_{\text {Hомо }}(\mathrm{eV})=-3.838417 \\
& \Delta \mathrm{E}=\mathrm{E}_{\text {LUMO }}-\mathrm{E}_{\text {Hомо }}=0.329 \\
& \text { Dipole moment }=28.93 \text { debye }
\end{aligned}
$$

Table 8. Comparison of the observed and calculated vibrational wavenumber $\left(\mathrm{cm}^{-1}\right)$ of $\mathrm{Cu}(\mathrm{Me}-\mathrm{dbm})_{2}$ bipy with PM3 method

\begin{tabular}{llllll}
\hline Mode & PM3 & PM3 & INT. & FT-IR & Assignments as in Table 6 \\
No & Calculated & Calculated & IR & Exp. & \\
& Unscaled & Scaled & & & \\
\hline 1 & 790.72 & 767 & 26.24 & - & $\gamma(\mathrm{C}-\mathrm{H})$ Phen $/$ bipy \\
2 & 792.16 & 768 & 179.29 & $764 \mathrm{w}$ & \\
3 & 797.32 & 777 & 30.40 & - & $\delta_{\text {as }}\left(\mathrm{CH}_{3}\right)+\delta_{\mathrm{s}}\left(\mathrm{CH}_{3}\right)$ \\
4 & 1442.63 & 1405 & 42.06 & $1400 \mathrm{~s}$ & $v_{\mathrm{s}}(\mathrm{C}-\mathrm{O})+\delta \mathrm{C}-\mathrm{H}$ \\
5 & 1485.90 & 1447 & 152.06 & $1455 \mathrm{~m}$ & \\
6 & 1498.69 & 1460 & 558.22 & - & $v_{\mathrm{s}}(\mathrm{C}-\mathrm{O})+\delta \mathrm{C}-\mathrm{H}$ \\
7 & 1523.18 & 1484 & 112.26 & $1484 \mathrm{~m}$ & \\
8 & 1536.51 & 1497 & 5.53 & - & $v_{\text {as }}(\mathrm{C}=\mathrm{O})+v_{\text {as }}(\mathrm{C}=\mathrm{C})$ \\
9 & 1539.15 & 1499 & 13.54 & - & $v_{\text {as }}(\mathrm{C}=\mathrm{O})+v_{\text {as }}(\mathrm{C}=\mathrm{C})$ \\
10 & 1589.84 & 1549 & 6.63 & $1525 \mathrm{~m}$ & \\
11 & 1601.65 & 1560 & 7.95 & $1546 \mathrm{~m}$ & $v_{\text {as }}(\mathrm{C}=\mathrm{O})+v_{\text {as }}(\mathrm{C}=\mathrm{C})$ \\
\hline 12 & 1604.66 & 1563 & 145.3 & - & \\
13 & 1609.33 & 1567 & 72.14 & - & $1594 \mathrm{~s}$ \\
\hline
\end{tabular}

$v_{\mathrm{s}}=$ symmetric stretching; $\gamma=$ out of plane bending; $\delta_{\mathrm{as}}=$ assymetric; Int $=$ IR intensity.

\section{Acknowledgements}

The authors are grateful to Third World Organisation for Women in Science and the Department of Chemistry/Chemical Engineering, Addis Ababa, Ethiopia for the Fellowship awarded and for the generous use of facilities, respectively. They also wish to acknowledge the Department of Chemistry University of Ibadan Nigeria for provision of chemicals and solvents.

\section{References}

Fackler Jr., J. P., Mittleman, M. I., Weigold, H., \& Barrow, G. M. (1968). Spectra of metal $\beta$-ketoenolates. The electronic spectrum of monomeric nickel(II) acetylacetonate and the infrared spectra of matrix-isolated acetylacetonates of cobalt(II), nickel(II), copper(II) and zinc(II). Journal of Physical Chemistry, 7(13), 
4631-4636. http://dx.doi.org/10.1021/j100859a046

Fan, D., Afzaal, M., Mallik, M., Nguyen, C., \& O’Brien, P. (2007). Using Coordination Chemistry to develop new routes to semiconductor and other materials. Coordination Chemistry Reviews, 251, 1878-1888. http://dx.doi.org/10.1016/j.ccr.2007.03.021

Gorbenko, O. Y., Troyanov, S. I., Meetsma, A., \& Bosak, A. A. (1997). Crystal structure of copper(II) pivaloyltrifluoroacetonate adducts with o-phenanthroline and 2,2'-dipyridyl. Polyhedron, 16(12), 1999-2004. http://dx.doi.org/10.1016/S0277-5387(96)00519-0

Graddon, D. P., \& Schulz, R. A. (1965). Adducts of copper(II) $\beta$-diketone chelates with heterocyclic bases. II. Chelates with 3-alkylacetylacetones. Australian Journal of Chemistry, 18, 1731-1742. http://dx.doi.org/10.1071/CH9651731

Hassan, W. M., Zayed, E. M., Elkholy, A. K., Moustafa, H., \& Mohamed, G. G. (2012). Spectroscopic and Density Functional Theory Investigation of Novel Schiff Base Complexes. Spectrochimica Acta Part A: Molecular and Biomolecular Spectroscopy, 103, 378-387.

Herrag, L., Hammouti B., Elkadiri, S., Aouniti, A., Jama, C., Vezin, H., \& Bentiss, F. (2010). Adsorption properties and inhibition of mild steel corrosion in hydrochloric solution by some newly synthesised diamine derivatives: Experimental and theoretical investigations. Corros. Sci., 52, 3042-3051. http://dx.doi.org/10.1016/j.corsci.2010.05.024

Hinckley, C. C. (1969). Paramagnetic shifts in solutions of cholesterol and the dipyridine adducts of trisdipivaloylmethanatoeuropium (III). A shift reagent. Journal of the American Chemical Society, 91(18), 5160-5162. http://dx.doi.org/10.1021/ja01046a038

Hinckley, C. C. (1970). Applications of rare earth nuclear magnetic resonance shift reagents. I. The assignment of the methyl proton magnetic resonance of d-camphor. Journal of Organic Chemistry, 35(8), 2834-2836. http://dx.doi.org/10.1021/jo00833a090

Holtzclaw, H. F. Jr., \& Collman, J. P. (1957). Infrared absorption of metal chelate compounds of 1,3-diketones. Journal of American Chemical Society, 79, 3318-3322. http://dx.doi.org/10.1021/ja01570a006

Johnson, P. R., \& Thornton, D. A. (1975). Electronic spectra of copper(II) $\beta$-ketoenolates: intraligand and charge transfer transitions. Journal of Molecular Structure, 29, 97-103. http://dx.doi.org/10.1016/0022-2860(75)88010-0

Karakas, D., \& Sayin, K. (2013). DFT and TD-DFT studies on copper(II) complexes with tripodal tetramine ligands. Indian Journal of Chemistry, 52A, 480-485.

Lever, A. B. P. (1986). Inorganic Electronic Spectroscopy (4th ed.). London: Elsevier.

Malecki, J. G., Machura, B., \& Switlicka, A. (2011). X-ray studies, spectroscopic characterization and DFT calculations for $\mathrm{Mn}(\mathrm{II}), \mathrm{Ni}(\mathrm{II})$ and $\mathrm{Cu}(\mathrm{II})$ complexes with 5,6-diphenyl-3-(2-pyridyl)-1,2,4-triazine. Struct Chem., 22, 77-87. http://dx.doi.org/10.1007/s11224-010-9686-7

Melnik, M., Potocnak, I., Macaskova, L., Miklos, D., \& Holloway, C. E. (1996). Spectral study of copper(II) flufenamates: crystal and molecular structure bis(flufenamato)di(N-N-diethylnicotinamide)di(aqua)copper(II). Polyhedron, $\quad 15, \quad 2159-2164$. http://dx.doi.org/10.1016/0277-5387(95)00486-6

Obot, I. B., \& Obi-Egbedi, N. O. (2010). Adsorption properties and inhibition of mild steel corrosion in sulphuric solution by Ketoconazole: Experimental and theoretical investigation. Corrosion Science, 52, 198-204. http://dx.doi.org/10.1016/j.corsci.2009.09.002

Odunola, O. A., Oladipo, M. A., Woods, J. A. O., \& Gelebe, A. C. (2003). Synthesis and structural studies of some ternary copper(II) complexes containing $\beta$-diketones with 1,10-phenanthroline and 2,2'-bipyridyl and x-ray structure of $\left[\mathrm{Cu}\left(\mathrm{C}_{6} \mathrm{H}_{5} \mathrm{COCHCOCH}_{3}\right)(\right.$ bipy)Cl]. Synthesis and Reactivity of Inorganic and Metal Organic Chemistry, 33(5), 857-871. http://dx.doi.org/10.1081/SIM-120021651

Patel K. S., \& Woods, J. A. O. (1990a). Synthesis and properties of nickel(II) complexes of various 3-alkyl-2,4-pentanediones and their adducts with 2,2-bipyridine and 1,10-phenanthroline. Synthesis and Reactivity in Inorganic and Metal-Organic Chemistry, 20(4), 409-424 and the references therein.

Patel, K. S., \& Woods, J. A. O. (1990b). Synthesis and physico-chemical properties of Bis(3-akyl-2,4-pentanedionato) copper(II) complexes and their adducts with 2,2'-bipyridine and 1,10-phenanthroline. Synthesis and Reactivity of Inorganic and Metal Organic Chemistry, 20(7), 909-922. 
http://dx.doi.org/10.1080/00945719008048184

Patel, K. S., \& Woods, J. A. O. (1990c). Preparation and physico-chemical studies of some 3-substituted-2,4-pentanedionato copper(II) complexes and their adducts. Synthesis and Reactivity of Inorganic and Metal Organic Chemistry, 20(1), 97-109. http://dx.doi.org/10.1080/00945719008049873

Perdew, J. P., Ruzsinszky, A., Tao, J., Staroverov, V. N., Scuseria, G. E., \& Csonka, G. I. (2005). Prescription for the desighn and selection of density functional approximations: More constraint satisfaction with fewer fits. Journal of Chemical Physics, 123, 62201-9. http://dx.doi.org/10.1063/1.1904565

Scott, A. P., \& Radom, L. (1996). Harmonic Vibrational Frequencies: An Evaluation of Hartree-Fock, Moller-Plesset, Quadratic Configuration; Density Functional Theory, and Semi empirical Scale Factors. $J$. Phys. Chem., 100, 16502-16513. http://dx.doi.org/10.1021/jp960976r

Shao, Y., Molnar, L. F., Jung, Y., Kussmann, J., Ochsenfeld, C., Brown, S. T., \& Martin Head-Gordon. (2006). Advances in methods and algorithms in a modern quantum chemistry program package. Phys. Chem. Chem. Phys., 8, 3172-3191.

Sheela, N. R., Sampathkrishnan, S., Kumar, M. T., \& Muthu, S. (2013). Synthesis, spectroscopic (FT-IR, FT-Raman, $\left.{ }^{13} \mathrm{C},{ }^{1} \mathrm{H}, \mathrm{UV}\right)$ study, first order hyperpolarizability, NBO analysis, HOMO and LUMO analysis of 2(2-Hydroxyphenyl)-N-(4-Methyphenyl)Nitrone. SpectrochimicaActa Part A: Molecular and Biomolecular Spectroscopy, 109, 272-281. http://dx.doi.org/10.1016/j.saa.2013.03.030

Tanaka, M., Shono, T., \& Shinra, K. (1969). Tautomerism in 3-substituted 2,4-pentanediones and their copper chelates. Bulletin of the Chemical Society of Japan, 42, 3190-3194. http://dx.doi.org/10.1246/bcsj.42.3190

Wenzel, T. J., Williams, E. J., Haltiwanger, R. C., \& Sievers, R. E. (1985). Studies of metal chelates with the novel ligand 2,2,7-trimethyl-3,5-octanedione. Polyhedron, 4(3), 369-378. http://dx.doi.org/10.1016/S0277-5387(00)86994-6

Woods, J. A. O., Omoregie, H. O., Retta, N., Chebude, Y., \& Capitelli, F. (2009). Synthesis and Physicochemical Studies of Nickel(II) Complexes of 2-substituted-1,3-diphenyl-1,3-propanedione, their 2,2'-bipyridine and 1,10-phenanthroline Adducts and X-Ray Structure of (2,2'-bipyridine)Bis(1,3-diphenyl-1, 3-propanedionato) Nickel(II). Synthesis and Reactivity in Inorganic, Metal-Organic, and Nano-Metal Chemistry, 39(10), 694-703.

Xu, Z., Gou, S. H., You, X. Z., Liu, S. X., Lin, C. C., Yu, Y. P., \& Zhu, D. L. (1991). Structure of a five-coordinate Copper(II) complex: ( 2,2'-bipyridine)[4,4,4-trifluoro-1-(2-thienyl)butane-1,3-dionato-O][ 4,4,4-trifluoro-1-(2-thienyl)butane-1,3 -dionato-O,O'] copper(II). Acta Cryst., C47, 81-83. http://dx.doi.org/10.1107/S0108270190005807

\section{Copyrights}

Copyright for this article is retained by the author(s), with first publication rights granted to the journal.

This is an open-access article distributed under the terms and conditions of the Creative Commons Attribution license (http://creativecommons.org/licenses/by/3.0/). 